ИЗВЕСТИЯ АКАДЕМИИ НАУК ЭСТОНСКОИ ССР. ТОМ 24 ХИМИЯ * ГЕОЛОГИЯ. 1975, № 1

\title{
О СОСТАВЕ ФРАКЦИИ СМОЛЫ ДИКТИОНЕМОВОГО СЛАНЦА МЕСТОРОЖДЕНИЯ ТООЛСЕ, ВЫКИПАЮЩЕЙ В ПРЕДЕЛАХ $190-270^{\circ} \mathrm{C}$
}

\author{
Данное сообщение является продолжением [1, 2].
}

\section{Экспериментальная часть}

\begin{abstract}
Фракция смолы, выкипающая в пределах $190-270^{\circ}$, выделялась при помощи дистилляции под вакуумом [2] из суммарной смолы, полученной полукоксованием диктионемового сланца в лабораторной реторте. Выход фракции $190-270^{\circ}$ составлял 29,8 вес. $\%$ смолы. Методом тонкослойной хроматографии указанная фракция разделялась на три группы: 1) парафины и олефины, 2) ароматические углеводороды и 3) кислородные соединения. Размеры пластинки $24 \times 24 \mathrm{~cm}$, толщина слоя силикагеля $L$ фирмы «Хемапол» 2 мм. Элюентом служил н-гексан. Выходы групп составляли $13,1,61,5$ и $21,1 \%$ фракции, выкипающей в пределах $190-270^{\circ}$, потери и полимеры - 4,3\%. Сернистые соединения концентрировались в ароматической части, содержащей $3,8 \%$ серы. Содержание последней в кислородных соединениях составляло $0,6 \%$.

Состав углеводородных групп исследовался при помощи «Хром-2»на капиллярной колонке $45 \mathrm{M} \times 0,25$ мм, покрытой полифениловым эфиром (ПФЭ), при ступенчатом программировании температуры колонки $\left(45-180^{\circ}\right)$. Газом-носителем служил азот со скоростью $0,5-1 \mathrm{M} / \mathrm{Muн}$, деление газовых потоков на входе в колонку составляло примерно $1: 200$.

Качественная и количественная расшифровка хроматограмм проводилась аналогично [3]. На основании результатов анализа парафино-олефиновой и ароматической частей рассчитывался состав углеводородной части фракции смолы, выкипающей в пределах 190-270. Кислородные и сернистые соединения не исследовались.
\end{abstract}

Хроматограмма парафино-олефиновой части изображена на рисунке.

\section{Результаты и их обсуждение}

Итоговые данные о составе фракции смолы диктионемового сланца месторождения Тоолсе, выкипающей в пределах $190-270^{\circ}$, приведены в таблице.

Всего идентифицировано 103 углеводорода, составляющие 44,1\% от фракцин, выкипающей в пределах 190-270.

Основные группы в идентифицированной части - углеводороды нафталинового ряда, алкилбензолы и н-алканы. 


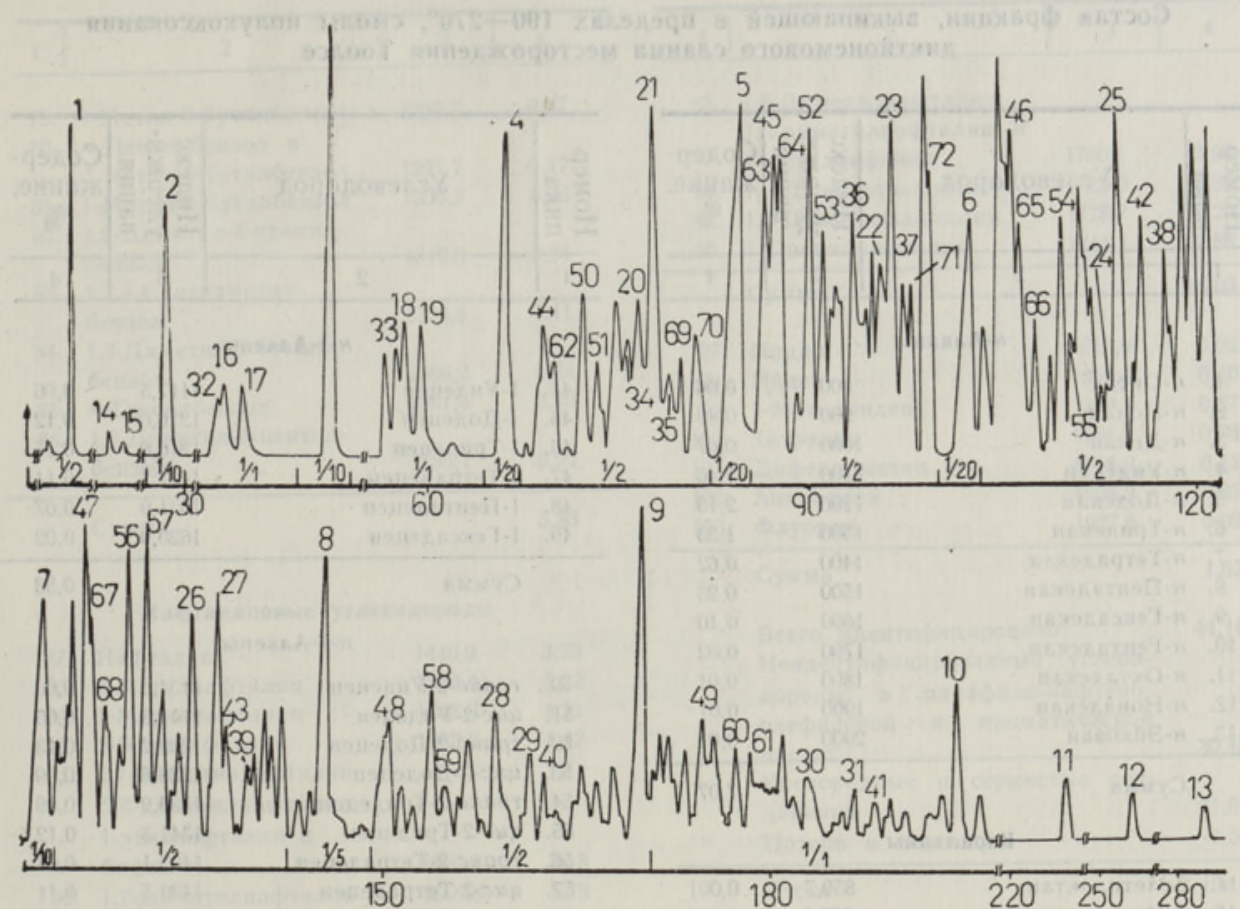

Хроматограмма парафино-олефнновой части фракции смолы диктионемового сланца месторождения Тоолсе, выкипающей в пределах $190-270^{\circ} \mathrm{C}$ (45-метровая капиллярная колонка с полифениловым эфиром). Обозначения пиков в таблице.

Преобладающими компонентами являются двухъядерные ароматические углеводороды - нафталин и его производные - метил-, этил-, диметил- и пропилнафталины, составляющие всего $26 \%$, т. е. $1 / 4$ фракции $190-270^{\circ}$.

Суммарное содержание алкилбензолов примерно в 4,5 раза меньше нафталинов и составляет лишь $5,8 \%$. Группа алкилбензолов состоит из ди- и триалкил- и тетраметилбензолов, а также $\boldsymbol{H}$-пентил- и $\boldsymbol{\mu}$-гексилбензолов.

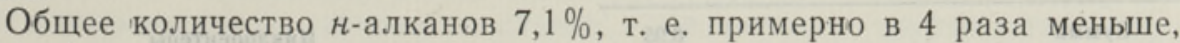
чем нафталинов, причем основными компонентами являются $\boldsymbol{H}$-ундекан $(1,5 \%)$, -додекан $(2,1 \%)$ и н-тридекан $(1,3 \%)$.

Суммарное содержание изоалканов $\sim 1 \%$, они представлены в основном 2- и 3-метилалканами $\mathrm{C}_{11}-\mathrm{C}_{16}$. Циклогексановые углеводороды обнаружены в большем количестве $(0,4 \%)$, чем циклопентаны $(0,1 \%)$.

Общее количество $\boldsymbol{H}$-алкенов незначительное $-1,4 \%$, т. е. примерно в 5 раз меньше, чем $\mu$-алканов, и в 18 раз меньше, чем нафталиновых углеводородов. Количество $H$-1-алкенов $(0,5 \%)$ в 1,5 раз меньше, чем $H$-2-алкенов, и в 14 раз меньше, чем $н$-алканов.

Циклогексены $(0,51 \%)$ и $H$-1-алкены $(0,5 \%)$ присутствуют в почти равных количествах, а содержание циклопентенов $(0,3 \%)$ примерно в 1,5 раза меньше, чем циклогексенов. В группе циклопентенов термодинамически более стабильные 1-алкил-1-циклопентены представлены в бо́льших количествах, чем 3-алкил-1-циклопентены.

В ароматической части идентифицированы еще тетралин, дифенилметан, аценафтен, флуорен, индан, инден и 1-метилинден. 
Состав фракции, выкипающей в пределах $190-270^{\circ}$, смолы полукоксования диктионемового сланша месторождения Тоолсе

\begin{tabular}{|c|c|c|c|}
\hline 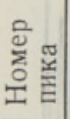 & Углеводород & 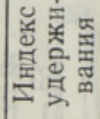 & $\begin{array}{c}\text { Содер- } \\
\text { жание, } \\
\%\end{array}$ \\
\hline 1 & 2 & 3 & 4 \\
\hline
\end{tabular}

н-Алканы

\begin{tabular}{lr} 
1. н-Октан & 800 \\
2. -Нонан & 900 \\
3. -Декан & 1000 \\
4. н-Ундекан & 110 \\
5. н-Додекан & 1200 \\
6. н-Трндекан & 1300 \\
7. н-Тетрадекан & 1400 \\
8. н-Пентадекан & 150 \\
9. н-Гексадекан & 1600 \\
10. -Гептадекан & 1700 \\
11. н-Октадекан & 1800 \\
12. н-Нонадекан & 1900 \\
13. н-Эйкозан & 2000 \\
\hline
\end{tabular}

Сумма

\section{Изоалканы}

\begin{tabular}{lrl} 
14. 2-Метилоктан & 859,7 & 0,001 \\
15. 3-Метилоктан & 867,8 & 0,001 \\
16. 2-Метилнонан & 963,1 & 0,003 \\
17. 3-Метилнонан & 970,0 & 0,003 \\
18. 2-Метилдекан & 1062,0 & 0,03 \\
19. 3-Метилдекан & 1068,6 & 0,02 \\
20. 2-Метилундекан & 1159,4 & 0,09 \\
21. 3-Метилундекан & 1165,0 & 0,18 \\
22. 2-Метилдодекан & 1263,3 & 0,10 \\
23. 3-Метилдодекан & 1268,3 & 0,10 \\
24. 2-Метнлтридекан & 1359,4 & 0,02 \\
25. 3-Метилтридекан & 1361,4 & 0,14 \\
26. 2-Метилтетрадекан & 1455,1 & 0,08 \\
27. 3-Метилтетрадекан & 1463,3 & 0,07 \\
28. 2-Метилпентадекан & 1556,2 & 0,05 \\
29. 3-Метилпентадекан & 1566,6 & 0,03 \\
30. 2-Метнлгексадекан & 1655,0 & 0,02 \\
31. 3-Метилгексадекан & 1669,8 & 0,01 \\
\hline & & 0,95
\end{tabular}

\section{Циклогексаны}

32. Изопропилциклогексан

33. Изобутилциклогексан

34. Изопентилциклогексан

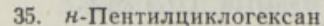

36. Изогексилциклогексан

37. $н$-Гексилциклогексан

38. н-Гептилциклогексан

39. н-Октилциклогексан

40. н-Нонилциклогексан

41. н-Децилциклогексан

\begin{tabular}{ccc} 
40. н-Нонилциклогексан & 1571,0 & 0,02 \\
41. н-Децилциклогексан & 1675,9 & 0,01 \\
\hline Сумма & & 0,36
\end{tabular}

\section{Циклопентаны}

\begin{tabular}{lll} 
42. н-Октилциклопентан & 1366,6 & 0,10 \\
43. н-Нонилциклопентан & 1466,1 & 0,04 \\
\hline Сумма & & 0,14
\end{tabular}

$\begin{array}{ll}1058,7 & 0,004 \\ 1154,7 & 0,05\end{array}$

$1172,5 \quad 0,03$

$1252,0 \quad 0,09$

$1272,8 \quad 0,06$

$1373,8 \quad 0,07$

$1473,8 \quad 0,02$

$1473,8 \quad 0,02$

\begin{tabular}{|c|c|c|c|}
\hline 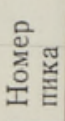 & Углеводород & 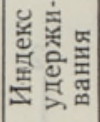 & $\begin{array}{c}\text { Содер- } \\
\text { жание, } \\
\%\end{array}$ \\
\hline 1 & 2 & 3 & 4 \\
\hline
\end{tabular}

\section{н-1-Алкены}

\begin{tabular}{lll} 
44. 1-Ундецен & 1117,5 & 0,06 \\
45. 1-Додецен & 1216,0 & 0,12 \\
46. 1-Трндецен & 1316,0 & 0,15 \\
47. 1-Тетрадецен & 1417,1 & 0,11 \\
48. 1-Пентадецен & 1521,9 & 0,07 \\
49. 1-Гексадецен & 1620,9 & 0,02 \\
\hline \multirow{2}{*}{ Сумма } & 0,53 \\
& &
\end{tabular}

50. транс-2-Ундецен

51. цис-2-Ундецен

52. транс-2-Додецен

53. цис-2-Додецен

54. транс-2-Тридецен

55. цис-2-Тридецен

56. транс-2-Тетрадецен $1433,1 \quad 0,08$

57. цис-2-Тетрадецен $1439,50,11$

58. транс-2-Пентадецен $\quad 1535,8 \quad 0,05$

59. цис-2-Пентадецен $\quad 1540,2 \quad 0,03$

60. транс-2-Гексадецен $1631,6 \quad 0,02$

61. цис-2-Гексадецен 1636,5 0,01

Сумма

0,84

\section{Циклогексены}

62. 1-Бутилциклогексен-1 $1122,6 \quad 0,03$

63. 3-Пентилциклогексен-1 1211,5 0,10

64. 1-Пентилциклогексен-1 $1219,0 \quad 0,11$

65. 3-Гексилциклогексен-1 $1319,1 \quad 0,07$

66. 1-Гексилциклогексен-1 $1324,0 \quad 0,03$

67. З-Гептнлциклогексен-1 1419,2 0,06

$\begin{array}{lll}\text { 68. } 1 \text {-Гептилциклогексен-1 } & 1423,8 & 0,05\end{array}$

Сумма

0,45

\section{Циклопентены}

69. З-Гексилциклопентен-1 $1177,7 \quad 0,02$

70. 1-Гексилциклопентен-1 $1183,6 \quad 0,06$

71. З-Гептилциклопентен-1 $1276,6 \quad 0,06$

\begin{tabular}{lll} 
72. 1-Гептилциклопентен-1 & 1284,2 & 0,13 \\
\hline Сумма & 0,27
\end{tabular}

\section{Алкилароматические углеводороды}

73. 1,2,3-Триметилбензол и

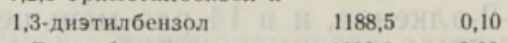

74. н-Бутилбензол $1192,6 \quad 0,02$

75. 1-Метил-2-пропилбензол

$1209,2 \quad 0,07$

76. 1,2-Диметил-4-9тилбензол $1229,1 \quad 0,22$

77. 1,2,4,5-Тетраметил- $1273,2 \quad 0,26$

78. 1,2,3,5-Тетраметилбензол

$1284,2 \quad 0,79$ 


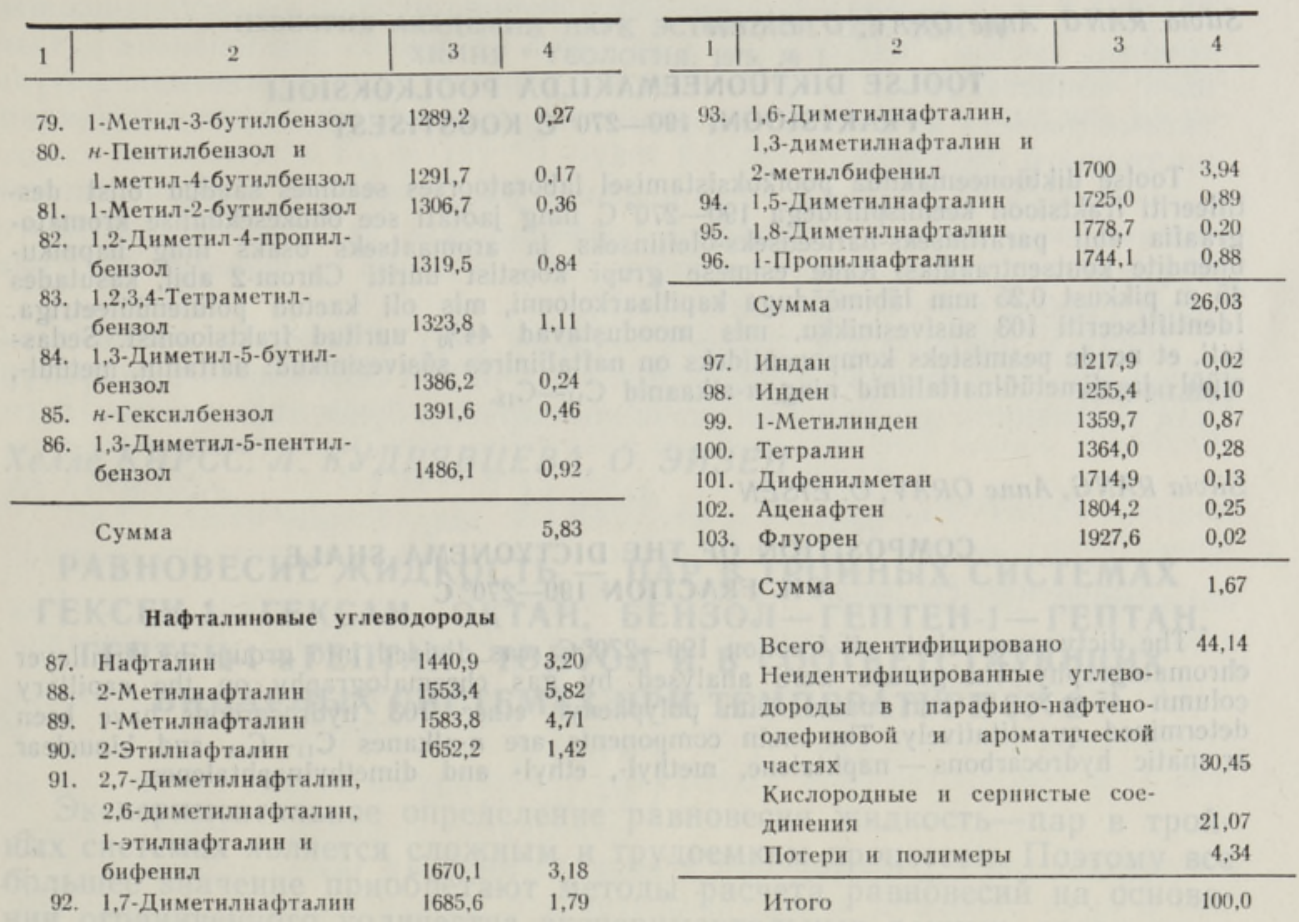

Преобладающими компонентами фракции смолы, выкипающей в пределах $190-270^{\circ}$, являются 1- и 2-метилнафталины, нафталин, этил- и диметилнафталины, 1 -пропилнафталин, 1,2,3,4-тетраметилбензол, $\boldsymbol{H}$-алканы $\mathrm{C}_{11}-\mathrm{C}_{13}$ и 1-метилинден. Остальные идентифицированные компоненты не превышают $0,8 \%$.

Из приведенных результатов видно, что фракция смолы полукоксования диктионемового сланца месторождения Тоолсе, выкипающая в пределах $190-270^{\circ}$, отличается от аналогичной фракции смолы туннельных печей (полученной из сланца-кукерсита) более высоким содержанием ароматических углеводородов и сернистых соединений и меньшим содержанием олефиновых углеводородов, в частности $\boldsymbol{H}$-алкенов, а также распределением изомерных $\boldsymbol{H}$-алкенов.

\section{Л И ТЕ РА Т У РА}

1. Ив анов А., Р анг С., Эйзен О., С тепин С., Изв. АН ЭССР, Хим. Геол., 22, 301 (1973).

2. Ранг С., Ор в в А., Ив анов А., Э йз ен О., Изв. АН ЭССР, Хим. Геол., 23, 27 (1974).

3. Р ан С С., Эй зен О., Ор ав А., Кунингас К., Тиикма а Т., Ив а нов А., Б а р а б н о в А., Изв. АН ЭССР, Хим. Геол., 22, 11 (1973).

Институт химии

Академии наук Эстонской ССР
Поступила в редакцию 26/VI 1973 
Silvia RANG, Anne ORAV, O. EISEN

\section{TOOLSE DIKTUOONEEMAKILDA POOLKOKSIÓLI FRAKTSIOONI $190-270^{\circ} \mathrm{C}$ KOOSTISEST}

Toolse diktüoneemakilda poolkoksistamisel laboratoorses seadmes saadud ōlist destilleeriti fraktsioon keemispiiridega $190-270^{\circ} \mathrm{C}$ ning jaotati see ōhukesekihilise kromatograafia abil parafiinseks-nafteenseks-olefiinseks ja aromaatseks osaks ning hapnikuühendite kontsentraadiks. Kahe esimese grupi koostist uuriti Chrom-2 abil, kasutades $45 \mathrm{~m}$ pik'ust $0,25 \mathrm{~mm}$ läbimõōduga kapillaarkolonni, mis oli kaetud polüfenüüleetriga. Identifitseeriti 103 süsivesinikku, mis moodustavad $44 \%$ uuritud fraktsioonist. Sedastati, et nende peamisteks komponentideks on naftaliinirea süsivesinikud: naftaliin, metüül-, etüül- ja dimetüülnaftaliinid ning $n$-alkaanid $\mathrm{C}_{11}-\mathrm{C}_{13}$.

Silvia RANG, Anne ORAV, O. EISEN

\section{COMPOSITION OF THE DICTYONEMA SHALE \\ OIL FRACTION $190-270^{\circ} \mathrm{C}$}

The dictyonema shale oil fraction $190-270^{\circ} \mathrm{C}$ was divided into groups by thin-layer chromatography. The groups were analysed by gas chromatography on the capillary column $45 \mathrm{~m} \times 0.25 \mathrm{~mm}$ coated with polyphenyl ether. 103 hydrocarbons have been determined quantitatively. The main components are $n$-alkanes $C_{11}-C_{13}$ and binuclear aromatic hydrocarbons - naphtalene, methyl-, ethyl- and dimethylnaphtalenes. 